\title{
Science that can change the world
}

\author{
Behavioural interventions leverage knowledge from basic research to improve important aspects of life, such as \\ healthy eating. Nature Human Behaviour is committed to working with researchers to disseminate the findings \\ from such important intervention studies as broadly as possible.
}

M ost people eat multiple times every day, which means that, over the course of a lifetime, each individual makes millions of decisions about what to consume. This has created a global food economy, full of companies that compete for our attention, be it through the placement of their products at the grocery store, advertisements in the subway or commercials on TV. These advertisements are clever, drawing on years of research on the psychology of persuasion and human desires to convince us to choose their brand and their food. However, these same resources can be used to design clever behavioural interventions that protect against such marketing strategies, taking advantage of people's natural inclinations to change their behaviour for the benefit of the individual.

Some of the same principles that underlie successful marketing form the basis of successful behavioural interventions. Importantly, introducing even a small change in behaviour can have large, real-world consequences. For example, convincing $0.1 \%$ of the American population to purchase another can of soda a week would result in over 17 million additional cans of soda sold. Similarly, reducing the average consumption of calories by $20 \mathrm{kcals}$ per day (which is less than a $1 \%$ change from the average consumed today) would reverse the obesity crisis, preventing millions of people from suffering from weight-related diseases such as heart disease, diabetes and cancer.

But how can we get people to make these changes on a large scale? Part of the answer lies in understanding the psychology of the group whose behaviour needs to be changed. For example, in this issue, Chris Bryan and colleagues leverage two important facts about adolescents to promote healthy eating behaviour in eighth-graders attending school in rural and suburban Texas (https://www.nature.com/

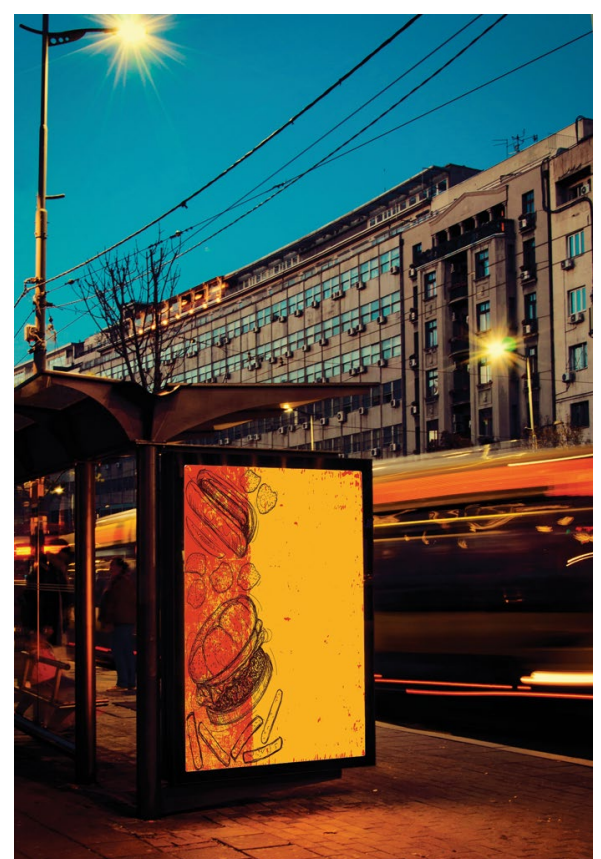

Credit: BURGER, retrorocket / Alamy Stock Vector; BUS STOP IMAGE, badmanproduction / iStock / Getty Images Plus / Getty

articles/s41562-019-0586-6) ${ }^{1}$. Anybody who remembers their own (or their children's or grandchildren's) adolescence can attest to the fact that adolescents generally want to be independent and out from under the yoke of adult control. They also care deeply about social justice. Leveraging these findings from basic psychology, Bryan and colleagues designed an intervention that showed adolescents that food marketing practices were designed by self-interested adults who wanted to make adolescents and other vulnerable populations buy junk food. By emphasizing the social injustice of junk food's targeting of children and vulnerable populations and the adults behind the marketing, this intervention spurred teens to do what is natural to them: reassert their autonomy by doing the opposite of what the adults want. However, in this case, the opposite was purchasing and eating healthy food rather than junk food. This intervention had the desired effect, especially in boys, who decreased their daily purchases of sugary drinks, chips and cookies by $31 \%$ and increased their healthy food profile by $35 \%$ (for more information, see this video about the paper: https://www.nature.com/nathumbehav/ videos/healthyeating).

This is an example of using basic knowledge about a population in order to tap into what some may call 'weaknesses for good'. However, such interventions are only possible when researchers designing the interventions are familiar with the basic science relating to their populations of interest and when scientists doing the basic research understand how their work can best be communicated so that the designers of the interventions utilize it to effect change. Nature Human Behaviour aims to be a forum for this exchange, publishing both basic science and intervention studies that we disseminate not only to researchers in diverse fields working at different levels but also to the general population. A small change cannot have a large impact unless we work together, across levels of science, publishing and policy to be sure that the type of exchanges that led to the success of Bryan and colleagues' study ${ }^{1}$ are encouraged, talked about and implemented at a large scale so that behavioural science can be used to change the world for better.

\section{Published online: 12 June 2019}

https://doi.org/10.1038/s41562-019-0642-2

\footnotetext{
References

1. Bryan, C. J., Yeager, D. S. \& Hinojosa, C. P. A values-alignment intervention protects adolescents from the effects of food marketing. Nat. Hum. Behav. https://www.nature.com/articles/ s41562-019-0586-6 (2019).
} 